\title{
Organosolv pretreatment of oat husk using oxalic acid as an alternative organic acid and its potential applications in biorefinery
}

\author{
Taner Sar $^{1}\left(\mathbb{D} \cdot\right.$ Vina Hasna Arifa $^{1,2} \cdot$ Muhammad Raihan Hilmy $^{1,2} \cdot$ Jorge A. Ferreira $^{1} \cdot$ Rachma Wikandari $^{2}$. \\ Ria Millati ${ }^{2} \cdot$ Mohammad J. Taherzadeh $^{1}$
}

Received: 26 October 2021 / Revised: 25 January 2022 / Accepted: 26 January 2022

(c) The Author(s) 2022

\begin{abstract}
In this study, ethanol organosolv treatment of oat husk and the potential effects of phosphoric acid and oxalic acid as alternatives to sulfuric acid were investigated. These acids were determined as effective as sulfuric acid to obtain high quality lignin and glucan and they can be used instead of sulfuric acid in solvent acidification. To determine the purity and recovery of both lignin and glucan, the effects of initial substrate amount, solid-to-liquid ratio, and amount of washing solutions were also examined using a one-factor-at-a-time strategy. Reducing the amount of washing solutions (water, solvent, or both) negatively affected lignin recovery, but it did not affect glucan recovery. The optimum conditions for pretreatment of the oat husk at higher glucan recovery were obtained with 50\% aqueous ethanol acidified with oxalic acid at $210{ }^{\circ} \mathrm{C}$ for $90 \mathrm{~min}$ and solid-to-liquid ratio of 1:2. In the mixture of evaporated glucan-rich and hemicellulose-rich fractions obtained through the optimized condition, $4.62 \mathrm{~g} / \mathrm{L}$ biomass containing $10.27 \%$ protein was produced by the cultivation of Aspergillus oryzae. The fractions obtained from organosolv treatment can be used to obtain value-added products such as biomass production, and thus contributing to a sustainable economy by integrating lignocellulosic substrate residues into the biorefinery.
\end{abstract}

Keywords Glucan recovery $\cdot$ Pretreatment $\cdot$ Oxalic acid $\cdot$ Biorefinery $\cdot$ Fungal biomass

\section{Introduction}

Agriculture has become an important resource to contribute to reducing poverty and improving the life standard of the world population with the encouragement of Food and Agricultural Organization (FAO) since 1945 [1]. Cereals (such as wheat, corn, rice, oats) are used as a traditional food source (such as flour) as well as in the preparation of new generation foods for nutrition [2]. Food by-products (husks and straws) rich in lignocellulose are generated during the processing of these cereals in food industries. Among them, 11 million tons of oats are grown worldwide, and oat husk containing high sugar content (2.75-3.3 million tons) are produced by the processing of oats [3, 4]. Lignocellulosic materials, including agricultural wastes and by-products, serve as a cheap and abundant feedstock. The discharge of these agricultural residues/by-products to the environment without treatment can pose a serious problem regarding environmental pollution due to their rich content (lignin, cellulose, hemicellulose, protein and starch) [5]. However, lignocellulosic compounds 


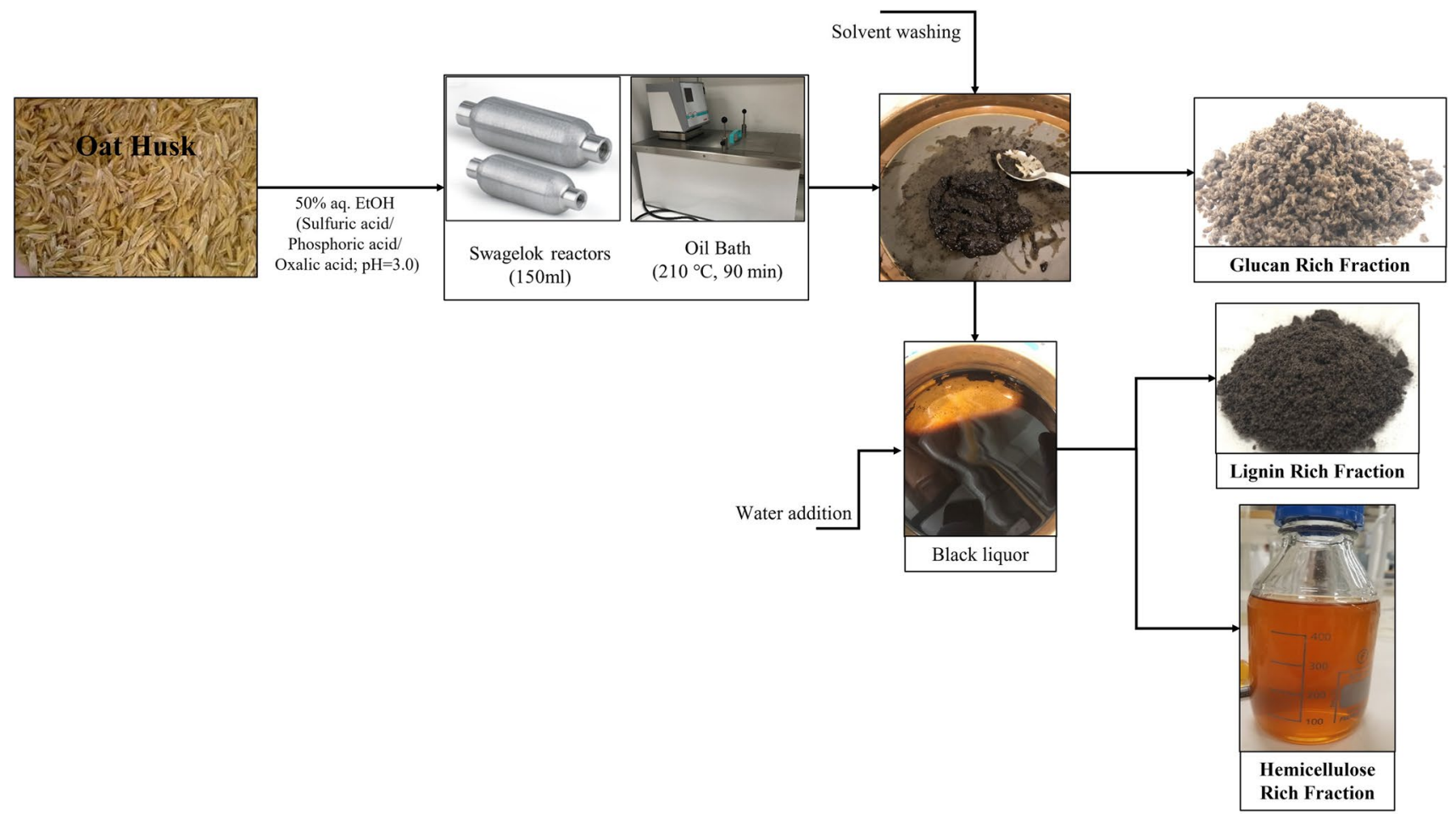

Scheme 1 Schematic representation of organosolv treatment of oat husk

can be converted into a wide variety of value-added products (biogas, bioethanol, acetone, butanol, enzyme, etc.) by microbial fermentation [6-9]. The use of lignocellulosic substrates in bioprocesses not only provides alternative substrates but also helps to solve pollution problems by their disposal [9, 10]. Recovery of lignocellulosic materials to the biorefinery requires a pretreatment step to remove the lignin barrier and recover the cellulose and hemicellulose fractions [11].

Pretreatment, i.e., conversion to fermentable sugar production, is one of the most important steps in converting lignocellulosic materials into valuable microbial products. Pretreatment strategies can be carried out by using the different methods such as physical, chemical, enzymatic or biological, or a combination of these [12]. Among the pretreatment methods, organosolv pretreatment can be considered advantageous as it can split lignocellulose into three high purity streams, namely, rich in glucan-, lignin-, and hemicellulose compounds fractions (Scheme 1) [5, 13, 14]. Although ionic liquids and deep eutectic solvents have been also used to obtain cellulose and lignin from lignocellulosic material, various types of cellulose (Avicel, microcrystalline cellulose (MCC), pre-hydrolysis sulfate pulp, $\alpha$-cellulose) are obtained. These differences change the characterization of cellulose as well as their molecular weight and morphology. On the other hand, this method does not guarantee high lignin extractability from lignocellulosic biomass [15]. Additionally, this technology suffers from high operating costs and the large amounts of water used. During biomass conversion, some degradation compounds considered toxic to microbial growth might be released from polysaccharides (e.g., furfural) and lignin (e.g., ferulic acid) [16]. Alternatively, the organosolv process can be considered as a promising method with its low chemical cost, easy recovery of solvents used at the end of the process, and providing high-quality glucan and lignin recovery [13]. The fractions of the organosolv treatment can be utilized for second-generation ethanol production and biomass production through filamentous fungi or baker's yeast, and the integration of these streams to plant also brings a net profit to the related production facility [17]. Filamentous fungal biomass, which can be obtained from a variety of substrates, can be normally used as an animal feed or food source with its high protein, essential amino acids, polyunsaturated fatty acids, vitamins, chitin/chitosan, and minerals contents [18]. Altogether, the potential of filamentous fungi as an alternative protein source needs to be investigated for the use of substrates such as glucan and hemicellulose fractions obtained by organosolv.

Sulfuric acid is mostly used to acidify the solvent in organosolv treatments [5, 14, 19-21]. However, its use in applications is limited due to its toxic, corrosive, dangerous, and inhibitory properties [22, 23]. Compared to sulfuric acid, phosphoric acid is advantageous to use because it has low corrosion effects, is less hazardous, and is low cost [24, 25]. More environmentally friendly organic acids (such as acetic acid, formic acid, and oxalic acid) can also be performed as catalyst [26, 27]. Among them, 
oxalic acid is of biological origin, which attracts attention due to its strong acidity and good complexing ability. Oxalic acid can not only be produced through microbial fermentation but also easily degraded compared to sulfuric acid [28]. Moreover, oxalic acid has the advantage of exhibiting less inhibitors and higher catalytic activity $[29,30]$. In a previous study conducted by Chopda et al. [5], ethanol acidified with sulfuric acid was studied as a solvent in organosolv treatment to obtain high purity lignin and glucan fractions from oat husk. As a continuation of this study, it was aimed to determine the potential effects of different catalysts (oxalic acid as an organic acid and phosphoric acid as a mineral acid) as an alternative to conventional sulfuric acid. In addition, the effects of the initial amount of substrate, solid-to-liquid ratio, and the amount of washing solutions used on glucan and lignin yields were investigated by using organic oxalic acid. Then, fungal biomass production was evaluated through Aspergillus oryzae and Neurospora intermedia cultivated in the organosolv fractions which give the highest glucan yield, so that fungal biomass could be evaluated in feed/food applications. Furthermore, the products obtained by organosolv treatment have been elaborated on how these can be evaluated in biorefinery.

\section{Materials and methods}

\subsection{Substrate}

The oat husk ( $1 \mathrm{~cm}$ length and $0.2 \mathrm{~cm}$ thickness) obtained from Lantmännen Agroethanol AB (Norköping, Sweden) was used as substrate for organosolv pretreatment. The glucan and lignin contents of oat husk were $24.78 \pm 0.88$ and $21.59 \pm 0.35 \%(\mathrm{~g} / \mathrm{g})$, respectively [5].

\subsection{Pretreatment}

The oat husk was pretreated in acidified ethanol solution (50\%, $\mathrm{v} / \mathrm{v}$ ) using 150-mL tubular stainless-steel reactors (Swagelok, El Paso, TX, USA). The effects of acid catalyst (sulfuric acid, phosphoric acid, and oxalic acid), initial amount of the substrate, and solid-to-liquid ratio (S/L; 1:2, 1:1, and 2:1, w/v) were studied. The reactors were placed in an oil bath (Bridge Mounted Circulator SE-Z, Julabo, Seelbach, Germany) and incubated for $90 \mathrm{~min}$ at $210{ }^{\circ} \mathrm{C}$ under static conditions [5]. Experiments were conducted using one factor strategy at a time.

After the incubation in the oil bath, the reactors were transferred to a container with ice and allowed to cool. The pretreated substrate from the cooled reactors was poured into a sieve $\left(0.25 \mathrm{~mm}^{2}\right.$ pore size) to separate it into solid (glucan-rich) and liquid (solvent, lignin-rich, and hemicelluloserich) phases (Scheme 1). The solid phase was washed with $28.3 \mathrm{~mL}$ of solvent/g of dry sample. This solvent was collected and then mixed with liquor. To precipitation of lignin, $56.6 \mathrm{~mL}$ of water/g of dry sample was added to the liquor [5,
14]. Then, the liquor was filtered by using a vacuum filtration to separate lignin-rich fraction and hemicellulose-rich fraction (Scheme 1). In addition, the effects of the amount of solvent and water (reducing water washing 50\%, reducing solvent washing 50\%, and reducing both water washing $50 \%$ and solvent washing 50\%) used for glucan and lignin recovery were also examined. All fractions were kept in the refrigerator at $4{ }^{\circ} \mathrm{C}$ until use. All cultivations were carried out in duplicate.

\subsection{Enzymatic hydrolysis}

Fractions rich in glucan and rich in hemicellulose compounds obtained in the best conditions were mixed and then evaporated using a rotary evaporator (LABO ROTA 20, Heidolph, Schwabach, Germany) at $110{ }^{\circ} \mathrm{C}, 40 \mathrm{rpm}$, and at a vacuum pressure of $100 \mathrm{mPa}$. The enzyme cocktail Cellic ${ }^{\circledR}$ Ctec3 (Novozymes, Denmark), with an activity of 222 filter paper units (FPU)/mL, was used at an enzyme loading of $10 \mathrm{FPU} / \mathrm{g}$ glucan $[5,14]$. The enzymatic hydrolysis experiments were carried out in $250-\mathrm{mL}$ sterile Erlenmeyer flasks containing $100 \mathrm{~mL}$ of the mixture adjusted to $\mathrm{pH} 5.2$, which were incubated at $50{ }^{\circ} \mathrm{C}$ for $48 \mathrm{~h}$ using a shaking water bath at $125 \mathrm{rpm}$. Hydrolysed substrates were used for fungal cultivation at the end of the enzymatic hydrolysis.

\subsection{Fungal cultivation}

In this work, Aspergillus oryzae var. oryzae CBS 819.72 and Neurospora intermedia CBS 131.92 were used for fungal cultivation. The fungal strains were maintained on PDA (Potato Dextrose Agar; $4 \mathrm{~g} / \mathrm{L}$ potato extract, $20 \mathrm{~g} / \mathrm{L}$ glucose, and $15 \mathrm{~g} / \mathrm{L}$ agar) medium agar. The agar plates were inoculated with $100 \mu \mathrm{L}$ spore solution which was evenly distributed onto the agar surface with another L-shape spreader. Then, the inoculated plates were incubated at $30^{\circ} \mathrm{C}$ for 3 days and then stored at $4{ }^{\circ} \mathrm{C}$ until use.

Fungal cultivations were performed by using $250 \mathrm{~mL}$ wide-neck Erlenmeyer flasks containing $100 \mathrm{~mL}$ of hydrolysed substrates. Each flask was inoculated with $2 \mathrm{~mL}$ of spore solution $\left(1.69 \times 10^{7}\right.$ and $6.30 \times 10^{5}$ spores $/ \mathrm{mL}$ for A. oryzae and $N$. intermedia, respectively), and incubated at $35{ }^{\circ} \mathrm{C}$ with orbital shaking at $125 \mathrm{rpm}$ for $120 \mathrm{~h}$ using a water bath. At the end of the cultivation, the broth was poured into a sieve $\left(1 \mathrm{~mm}^{2}\right.$ pore size) and the retained fungal biomass was washed with distilled water. All cultivations were carried out in duplicate.

\subsection{Analytical methods}

The total solids (TS), dissolved solids (DS), and ash contents were determined according to Sluiter et al. [31]. The 
recovery and purity of the lignin-rich and glucan-rich fractions were also analyzed according to previous work [5]. The nitrogen content of the substrate and biomass was analyzed by using the Kjeldahl method, and the crude protein of the biomass was calculated by a factor of 6.25 [32]. The COD levels were determined using a COD Kit (Nanocolor® COD 15,000, Düren, Germany).

The HPLC system (Waters 2695, Milford, MA, USA) equipped with a refractive index detector (Waters 2414, Milford, MA, USA) was used for determining the sugars, acids, and alcohols. The determination of acids, alcohols, and glucose was carried out by using an analytical ion exchange column based on hydrogen ions (Aminex HPX-87H, BioRad, Hercules, CA, USA) operating at $60{ }^{\circ} \mathrm{C}$ with $0.6 \mathrm{~mL} /$ min of $5 \mathrm{mM} \mathrm{H}_{2} \mathrm{SO}_{4}$ as the eluent.

\subsection{Statistical analysis}

The software Minitab17® was used for the statistical analysis of the obtained results with ANOVA (analysis of variance). Pairwise comparisons among groups of data were also carried out using the Tukey test. Significant differences were considered at $p$-value $<0.05$ within a $95 \%$ confidence interval. All error bars and intervals presented represent two times the standard deviation.

\section{Results and discussion}

The oat husk was separated through acid-catalyzed ethanol organosolv pretreatment into three high-quality streams which are glucan-rich, lignin-rich, and hemicellulose compounds-rich fractions. First, the effects of phosphoric acid and oxalic acid as catalysts were investigated due to their lower corrosion and toxicity activities than sulfuric acid. Then, oxalic acid was used in all subsequent pretreatment experiments because it is an effective catalyst for glucan purity and recovery and also is known as safe organic acid. The other pretreatment factors such as acid concentration, initial amount of substrate, solid-to-liquid ratio, and amount of washing solutions (water and solvent) on lignin/glucan purity and recovery were investigated. A mixture of evaporated fractions rich in glucan and hemicellulose compounds obtained in the best pretreatment condition was evaluated for fungal biomass production.

\subsection{Effects of catalyst type and concentration}

In order to evaluate the effects of catalysts (sulfuric acid, phosphoric acid, and oxalic acid) in ethanol organosolv pretreatment of oat husk, such parameters of 36.36 initial substrate amount, $1: 2$ solid-to-liquid ratio, $210{ }^{\circ} \mathrm{C}$, and $90 \mathrm{~min}$ were used [5]. All three different acids were treated with solvent such that their initial $\mathrm{pH}$ values were adjusted to 3.00 (Fig. 1a, b) or their acid concentrations $(0.0001428 \mathrm{~g}$ acid/g sample) were the same (Fig. 1c, d). Different types of acid catalysts ( $\mathrm{pH}$ 3.0) had no significant effect on lignin purity, lignin recovery, and glucan purity (Fig. 1a, b). Similarly, Mondylaksita et al. [14] reported that different acids (sulfuric acid and acetic acid) as catalysts did not affect the lignin purity in their organosolv treatment; however, acetic acid could be considered as a more efficient catalyst regarding the lignin recovery. In this study, it was also determined that there was a statistically significant increase in glucan recovery with phosphoric acid and oxalic acid compared to sulfuric acid ( $p=0.014$, Fig. 1b). Dicarboxylic organic acids can hydrolyse polymers of $\beta$ - $(1,4)$-glycosidic bonds more than sulfuric acid at equivalent solution $\mathrm{pH}[33,34]$.
Fig. 1 Effect of the catalyst type (sulfuric, phosphoric, and oxalic acid) on the yields of lignin purity and recovery and glucan purity and recovery. a and $\mathbf{b}$ represent the initial $\mathrm{pH}$ of the solvents as 3.0 (at different acid concentrations); $\mathbf{c}$ and $\mathbf{d}$ represent the initial $\mathrm{pH}$ of the solvents as 3.0, 3.5, and 3.2 (at same final acid concentrations) for sulfuric, phosphoric, and oxalic acid, respectively. All experiments were performed in duplicate, and error bars indicate sample standard deviations. Different letters indicate significant $(P<0.05)$ differences
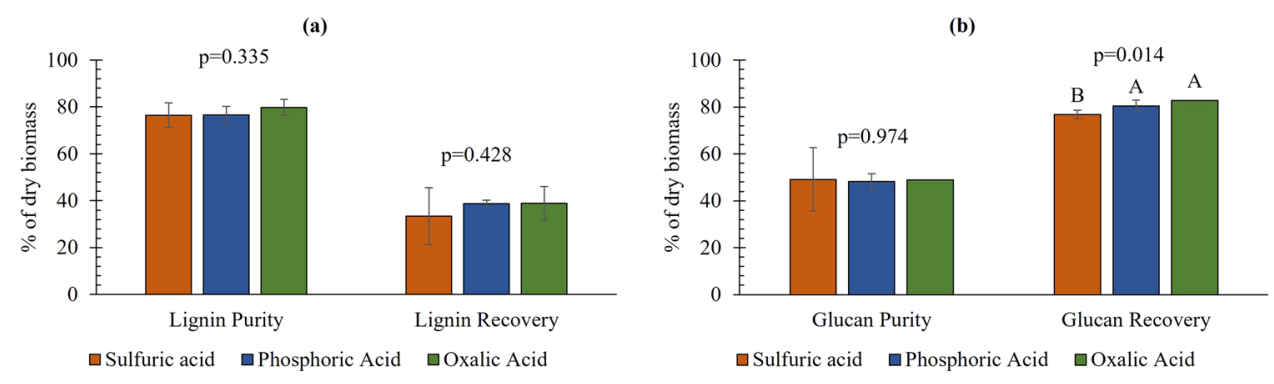

(c)
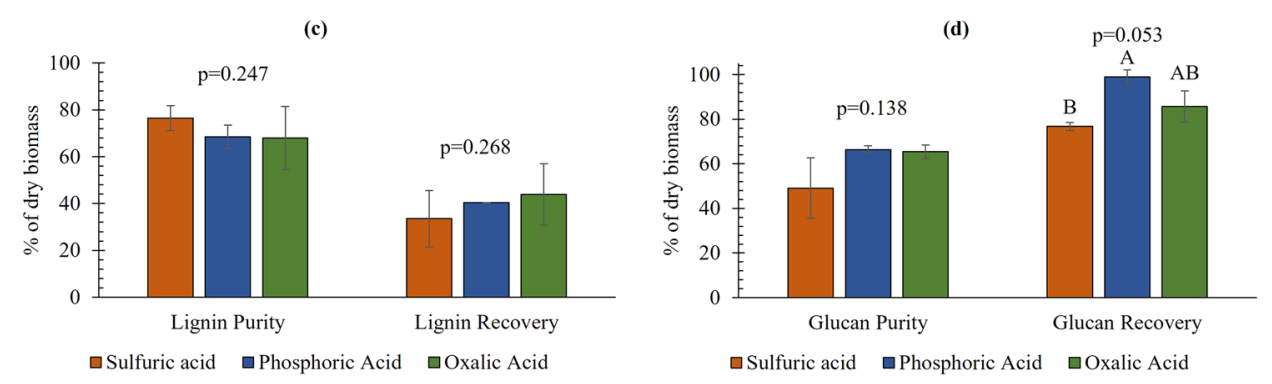
Similarly, oxalic acid was found to be more effective than sulfuric acid in the hydrolysis of substrates such as beech and bamboo $[35,36]$.

The initial amount of acid is one of the parameters affecting the efficiency of the organosolv pretreatment [19, 37]. Hence, in this study, the solvents were reprepared with the same amount of acid and the $\mathrm{pH}$ values of the solvents varied according to the amount of acid $(\mathrm{pH}$ values of sulfuric, phosphoric acid oxalic acids were 3.00, 3.50, and 3.22, respectively). Solvents prepared using the same amount of acid (phosphoric or oxalic acid) had a negative effect on lignin purity, although it did not make any change on lignin recovery (Fig. 1c). Similarly, concentrations only had a slight effect on the amount of lignin and pulp at values of 0.02-2 $\mathrm{N} \mathrm{H}_{2} \mathrm{SO}_{4}$ for pretreating wheat straw [37]. On the other hand, it was determined that these solvents had a partially positive effect ( $p=0.053$ ) on glucan purity and recovery (Fig. 1d). The glucan fraction of the biomass may be partially hydrolysed at high acid concentrations. It was recommended that the final $\mathrm{pH}$ of the organosolv liquor could not be less than about 3.5 to prevent cellulose hydrolysis [38]. Yawalata and Paszner [39] also suggested that a pH between 3.8 and 4.2 could be optimal for organosolv treatment of soft wood pulping. In this study, it was found that the $\mathrm{pH}$ value of the solvent could be 3.5 for phosphoric acid and 3.2 for oxalic acid to obtain high glucan recovery from oat husk.

\subsection{Effects of initial substrate amount and solid-to-liquid ratio}

In organosolv treatment, many parameters such as solvent type and concentration, solid-to-liquid ratio, incubation time, and temperature can affect the glucan yield [13]. In addition, the use of high substrate concentration affects product quality such as surface area, pore size, and polymerization degree (DP) [40]. For oat husk's organosolv pretreatment, two different initial substrate amounts $(36.36 \mathrm{~g}$ vs. $18.18 \mathrm{~g}$ [5]) were applied using $\mathrm{S} / \mathrm{L}$ of $1: 2$ and oxalic acid as catalyst. Reducing the initial substrate amount by half resulted in an increase in lignin and glucan recoveries by $46 \%$ and $23 \%$, respectively (Fig. 2a, b). Here, the increased yield is likely to be achieved by increasing the amount of acid per gram substrate. In relation to this result, there was a statistically decrease in glucan recovery since the amount of acid per gram of substrate was significantly reduced with increasing of solid contents (S/L; 1:2, 1:1, 2:1) (Fig. 2d). Similar reductions in glucan yield occurred when the total amount of solvent and substrate in the reactor was made up to $50 \mathrm{~mL}$ (at different S/L values) (Fig. 2f). The optimum S/L ratio to
Fig. 2 The yields of lignin purity and recovery and glucan purity and recovery at varying parameters: $\mathbf{a}$ and $\mathbf{b}$ represent the effects of initial amount of substrate (36.36 $\mathrm{g}$ and 18.18), $\mathbf{c}$ and $\mathbf{d}$ represent the effects of solid-to-liquid ratios (1:2, 1:1, and 2:1), $\mathbf{e}$ and $\mathbf{f}$ represent the effects of solid-to-liquid ratios (1:2, 1:1, and 2:1) with different initial amounts of substrate. All experiments were performed in duplicate, and error bars indicate sample standard deviations. Different letters indicate significant $(P<0.05)$ differences (a)

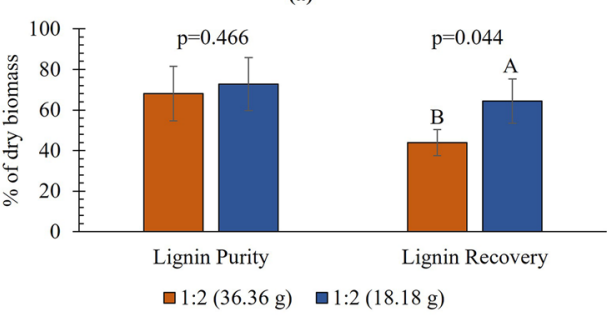

(c)

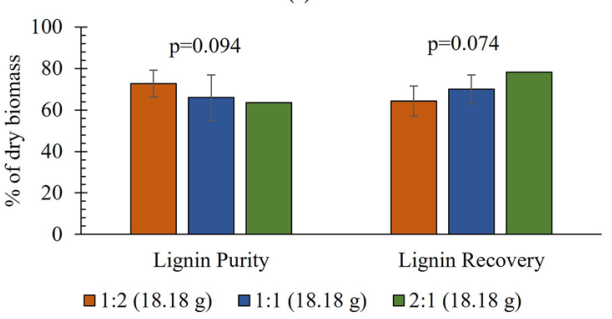

(e)

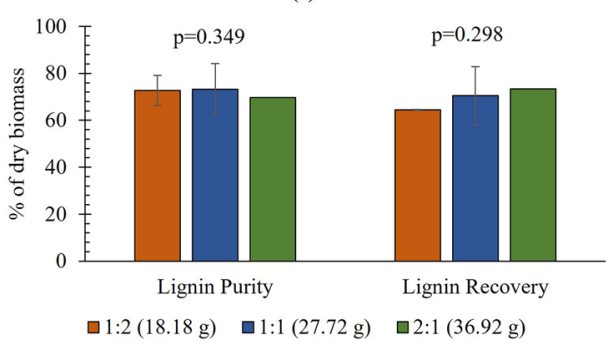

(b)

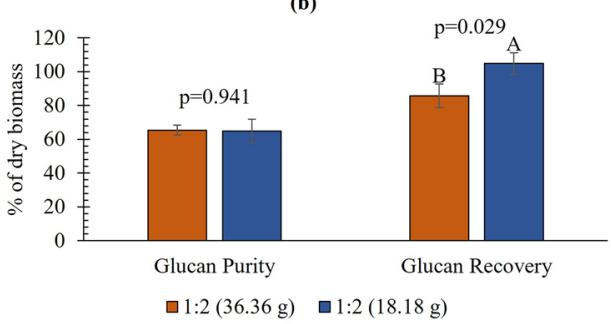

(d)

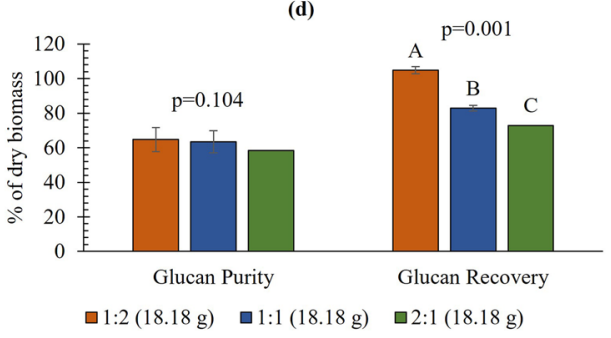

(f)

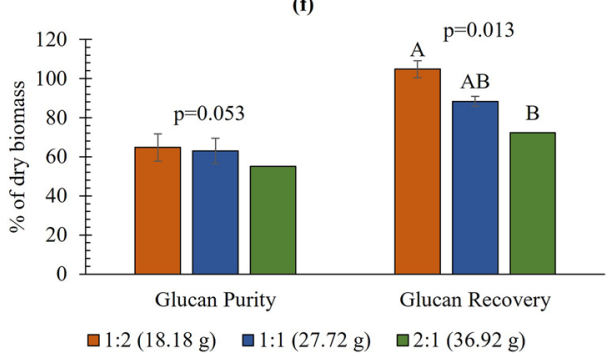


(a)

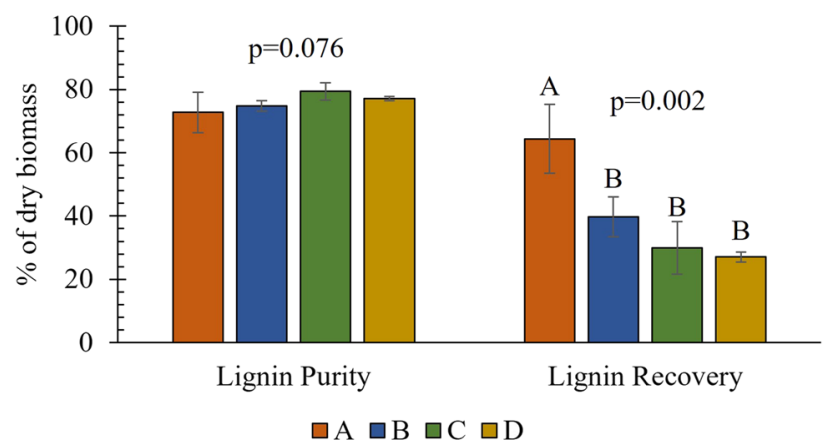

(b)

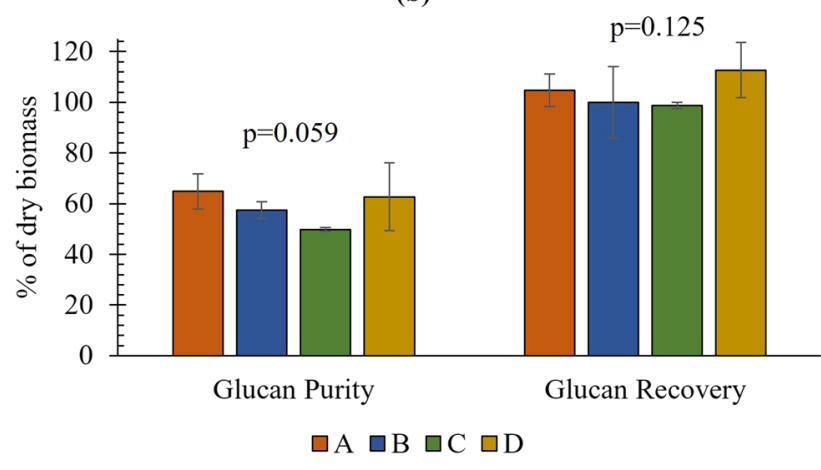

Fig. 3 Effects of amount of washing solutions (A. without reduction, B. reducing water washing by $50 \%, \mathrm{C}$. reducing solvent washing by $50 \%$, reducing both water and solvent washing by $50 \%$ ) on a lignin purity and recovery and $\mathbf{b}$ glucan purity and recovery. All experiments were performed in duplicate, and error bars indicate sample standard deviations. Different letters indicate significant $(P<0.05)$ differences

recovery and purity of glucan or lignin may vary depending on the substrate used; for example, different $\mathrm{S} / \mathrm{L}$ values have been suggested such as 1:2 for oat husk [5], 1:5 for cornstalk [17], 1:10 for oil palm empty fruit bunch [14], and 1:20 for horticulture [41]. In this study, the optimum parameters for oxalic acid-catalyzed glucan recovery from oat husk were $18.18 \mathrm{~g}$ initial substrate and 1:2 solid-liquid ratio. Organosolv treatment was continued with these optimum conditions in determining the effects of the amount of washing solution.

\subsection{Effects of washing amount}

Solvents used in organosolv treatment processes should be removed from the system. Extraction and separation techniques are used for this, but this distillation process also affects the operating cost $[42,43]$. Although the solvent can be recovered to a large extent at the end of the process, it is not economically viable for the business [41]. In addition to solvent, a large amount of water is required for the precipitation of lignin [44]. The effects of these washing solutions (water and solvent) on the purity and recovery of glucan and lignin were investigated by reducing the amount of water, solvent, and both solutions by $50 \%$, separately. The reduction of washing solutions (water or solvent) had no adverse effect on lignin purity $(72.7-79.4 \%, p=0.076)$, while lignin recoveries were reduced from 64.4 to $27.1 \%$ $(p=0.002)$ (Fig. 3a). Although it was determined that the reducing amount of solvent or water by $50 \%$ reduced the glucan purity by $11.3-23.1 \%$ (Fig. 3b), these reductions were not statistically significant $(p=0.059)$. Similarly, the amount of washing solution had no effect on glucan recovery ( $p=0.125$, Fig. $3 b)$. Since reductions in the amount of washing (water or solvent) do not affect glucan recovery, bioprocesses using glucan will therefore not be affected. To this end, Bulkan et al. [17] reported that a company producing ethanol and fungal biomass from glucan can have a 3.32fold increase in net present value in 20 years, by reducing the amount of solvent and water in pulp washing. On the other hand, since reducing the amount of washing affects the recovery of lignin, it may also affect the usage areas of lignin and the sale price of lignin.

\subsection{Fungal cultivation}

A mixture of fractions rich in glucan and hemicellulose compounds obtained under optimum conditions for high glucan purity and recovery was evaporated and then digested using $10 \mathrm{FPU}$ of Cellic $₫$ Ctec 3 enzyme per gram of glucan, for $48 \mathrm{~h}$. After the enzymatic hydrolysis, this hydrolysed mixture was evaluated for fungal cultivation
Fig. 4 A. oryzae cultivation on the mixture of glucan and hemicellulose compounds rich fractions obtained from organosolv pretreatment; a fungal biomass production and $\mathbf{b}$ consumption of glucose and other metabolites. All experiments were performed in duplicate, and error bars indicate sample standard deviations (a)

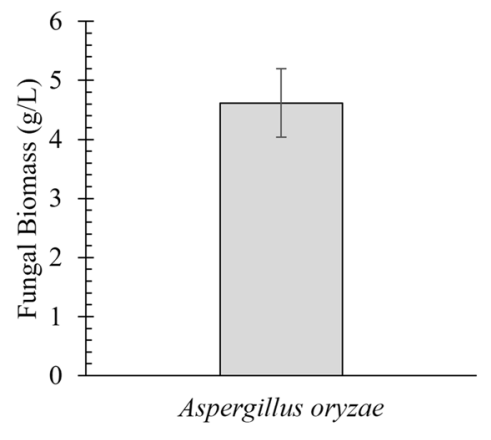

(b)

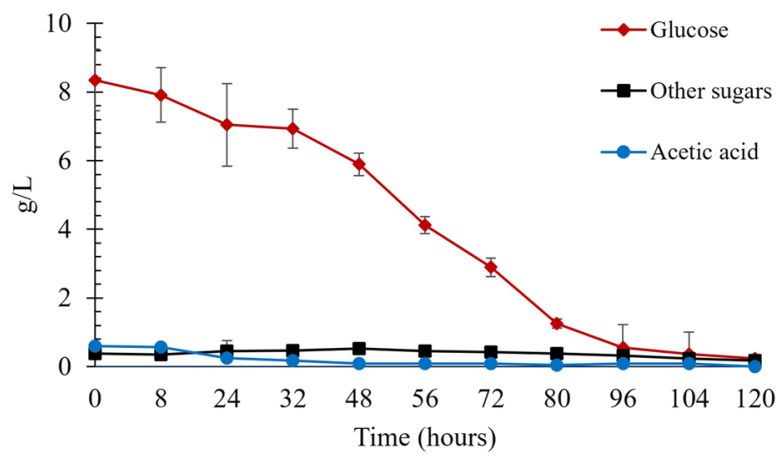


Table 1 Characterization of initial substrate (the mixture of glucan and hemicellulose compounds rich fractions) and the remaining stream following cultivation of $A$. oryzae and biomass separation

\begin{tabular}{lll}
\hline & Initial & After cultivation \\
\hline $\mathrm{pH}$ & - & $7.26 \pm 0.03$ \\
$\mathrm{COD}(\mathrm{g} / \mathrm{L})$ & $44.50 \pm 1.41$ & $14.25 \pm 1.73$ \\
Total solid $(\mathrm{g} / \mathrm{L})$ & $21.93 \pm 1.97$ & $10.13 \pm 0.85$ \\
Dissolved solid $(\mathrm{g} / \mathrm{L})$ & $4.51 \pm 0.37$ & $5.94 \pm 0.13$ \\
Volatile solid $(\mathrm{g} / \mathrm{L})$ & $18.80 \pm 1.60$ & $7.78 \pm 0.43$ \\
Ash $(\mathrm{g} / \mathrm{L})$ & $2.54 \pm 0.22$ & $2.10 \pm 0.06$ \\
Nitrogen $\mathrm{g} / \mathrm{kg}$ & $0.19 \pm 0.08$ & $0.29 \pm 0.03$ \\
\hline
\end{tabular}

by $A$. oryzae and $N$. intermedia. At the end of the cultivation, biomass production and glucose consumption were not observed in the medium in which $N$. intermedia was inoculated. On the other hand, $4.62(\mathrm{~g} / \mathrm{kg})$ biomass containing $10.3 \%$ protein was obtained through A. oryzae cultivation (Fig. 4a). In addition, glucose was consumed by $93.3 \%$ and $97.2 \%$ after 96 and $120 \mathrm{~h}$ of incubation, respectively (Fig. 4b). In contrast, Marhendraswari et al. [45] reported that the growth ability with glucose consumption of Rhizopus delemar in the substrate obtained by organosolv treatment was very slow, but the efficiency of fungal biomass was increased with additional nutrients (yeast, minerals, and trace elements). Although nutritional supplementation is not required for the cultivation of Aspergillus yielding $0.55 \mathrm{~g}$ biomass/g glucose, it may be necessary for the cultivation of Neurospora. However, nitrogen sources could improve amino acids, purines, pyrimidines, and enzyme cofactors syntheses for required to microbial growth [46]. Sar et al. [47] also reported that the addition of sodium nitrate as a nitrogen supplementation could reduce incubation time from 96 to $48 \mathrm{~h}$ and increase the protein content of biomass from 15.9 to $29.5 \%$, whereas the supplementation did not affect the total amount of $A$. oryzae biomass from olive oil mill wastewater. Therefore, some additional nitrogen sources can be evaluated to shorten the incubation time and increase the amount of protein of A. oryzae.

The composition of organosolv-treated substrate was given in Table 1. After the fungal cultivation, the levels of total solids and COD were removed by $53.8 \%$ and $68.0 \%$, respectively. Similarly, COD levels was successfully reduced when A. oryzae was cultivated on different substrates such as fish industry side-streams, olive oil mill wastewater, vinasse, and starch plant wastewater. [47-50].

\subsection{Biorefinery of organosolv treated fractions}

A total of $247.8 \mathrm{~kg}$ of glucan and $215.9 \mathrm{~kg}$ of lignin can be theoretically obtained from 1 ton of oat husk considering the glucan and lignin contents of oat husk. According to the organosolv results obtained in this study, 244.7 to $247.8 \mathrm{~kg}$ of glucan (with a purity between 49 and 64\%) and 58.5 to $139 \mathrm{~kg}$ of lignin (with a purity between 72 and $79 \%$ ) can be obtained depending on the amount of washing solutions. Then, the mixture of glucan and hemicellulose rich fractions was used for the cultivation of $A$. oryzae and theoretically yielded $105.4 \mathrm{~kg}$ of dried biomass from
Fig. 5 Potential uses of fractions (glucan, hemicellulose, and lignin) obtained after organosolv pretreatment in biorefinery

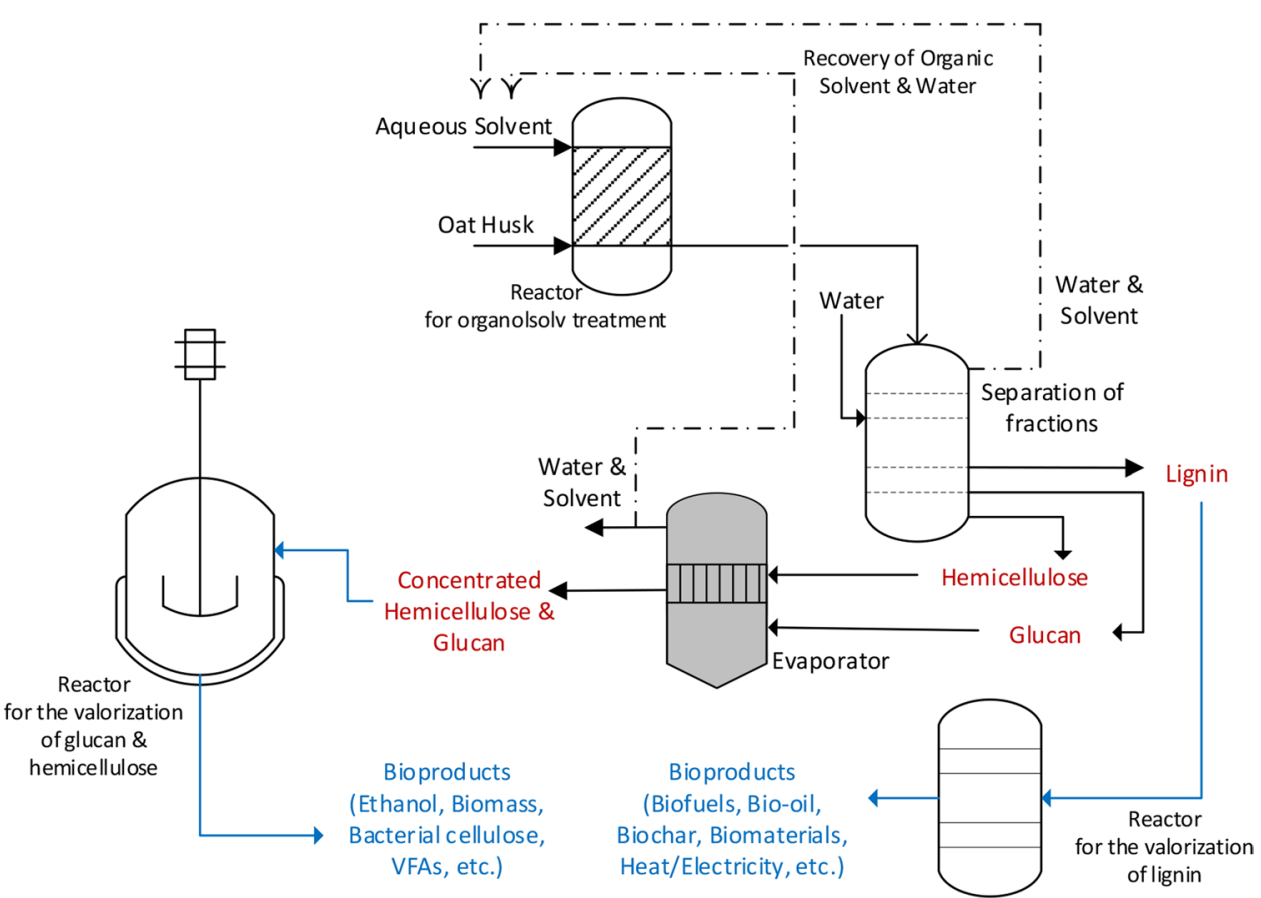


1 ton of oat husk. The obtained biomass can be evaluated as an animal feed additive or as a high-quality feed or food by increasing the protein content. It can be mixed with different nitrogen-rich substrates (e.g., thin stillage, fish industry wastes $[17,32,48]$ ) to increase the protein content of the biomass, and then the mixture streams integrated into fungal biomass production facilities. Besides the potential for biomass production, organosolv fractions can also be used to produce some value-added products (Fig. 5) and contribute to the integrated production facilities [13, 17, 51, 52]. Furthermore, the use of ethanol as a solvent facilitates the possibility of process integration in ethanol plants, and the recovery of ethanol from organosolv treatment benefits the existing equipment in the ethanol plant $[5,17]$.

Lignin is also an attractive material to produce biofuels, carbon fibers, thermoplastic compounds, bio-based binding agent, and polyurethane foams (reviewed in [13, 53, 54]). On the other hand, lignin can be commercially sold and costs between 0.6 and 1.0 dollars per kilogram depending on its purity [17]. Conversion of lignin to biofuels/biochemicals or its commercial sale will provide additional income or energy savings for the facility.

\section{Conclusions}

In this study, the use of oxalic acid as a catalyst in the organosolv process was effective in glucan purity and recovery, and it was also evaluated as an alternative to conventional sulfuric acid as it is known as a safe organic acid. Initial substrate amount and solid-to-liquid ratio were found to be critical parameters on yields of glucan recovery. On the other hand, reducing the amount of washing solutions (water and solvent) affected the lignin recovery efficiency but not the glucan recovery efficiency. With glucan recovery, it was determined that $244.7 \mathrm{~kg}$ of glucan and then $105.4 \mathrm{~kg}$ of fungal biomass could be obtained per ton by treating the oat husk with organosolv pretreatment. The results showed that the organosolv fractions could be potentially used in biorefinery to produce fungal biomass. Further research including large-scale reactor and techno-economic analysis may also be carried out.

Author contribution Conceptualization: Taner Sar, Jorge A. Ferreira, and Mohammad J. Taherzadeh; Methodology: Taner Sar, Vina Hasna Arifa, and Muhammad Raihan Hilmy; Formal analysis and investigation: Taner Sar, Vina Hasna Arifa, and Muhammad Raihan Hilmy; Writing - original draft preparation: Taner Sar; Writing — review and editing: Taner Sar, Rachma Wikandari, Ria Millati, and Mohammad J. Taherzadeh; Supervision: Jorge A. Ferreira, Rachma Wikandari, Ria Millati, and Mohammad J. Taherzadeh, Projection administration: Mohammad J. Taherzadeh.
Funding Open access funding provided by University of Borås. This research was funded by the Swedish Agency for Economic and Regional Growth through a European Regional Development Fund.

\section{Declarations}

Conflict of interest The authors declare no competing interests.

Open Access This article is licensed under a Creative Commons Attribution 4.0 International License, which permits use, sharing, adaptation, distribution and reproduction in any medium or format, as long as you give appropriate credit to the original author(s) and the source, provide a link to the Creative Commons licence, and indicate if changes were made. The images or other third party material in this article are included in the article's Creative Commons licence, unless indicated otherwise in a credit line to the material. If material is not included in the article's Creative Commons licence and your intended use is not permitted by statutory regulation or exceeds the permitted use, you will need to obtain permission directly from the copyright holder. To view a copy of this licence, visit http://creativecommons.org/licenses/by/4.0/.

\section{References}

1. Fao, Strategic work of FAO to reduce rural poverty. 2017, Food and Agriculture Organisation of the United Nations Rome.

2. Saikia D, Deka SC (2011) Staple food to neutraceuticals. Int J Food 18:21-30

3. Chaud LCS, Silva DDVD, Mattos RTD, Felipe MDGDA (2012) Evaluation of oat hull hemicellulosic hydrolysate fermentability employing Pichia stipitis. Braz Arch Biol Technol 55:771-777

4. Demirel F, Germec M, Coban HB, Turhan I (2018) Optimization of dilute acid pretreatment of barley husk and oat husk and determination of their chemical composition. Cellulose 25(11):6377-6393

5. Chopda R, Ferreira JA, Taherzadeh MJ (2020) Biorefining oat husks into high-quality lignin and enzymatically digestible cellulose with acid-catalyzed ethanol organosolv pretreatment. Processes 8(4):435

6. Cortivo PRD, Hickert LR, Hector R, Ayub MAZ (2018) Fermentation of oat and soybean hull hydrolysates into ethanol and xylitol by recombinant industrial strains of Saccharomyces cerevisiae under diverse oxygen environments. Ind Crops Prod 113:10-18

7. Machado TB, Junior LCSC, Gautério GV, Kalil SJ (2021) Sequential alkaline and ultrasound pretreatments of oat hulls improve xylanase production by Aureobasidium pullulans in submerged cultivation. Waste Biomass Valor, 1-14.

8. Chen WH, Nižetić S, Sirohi R, Huang Z, Luque R et al. (2022) Liquid hot water as sustainable biomass pretreatment technique for bioenergy production: a review. Bioresour Technol, 344:126207.

9. Hoang AT, Nizetic S, Ong HC, Chong CT, Atabani AE (2021) Acid-based lignocellulosic biomass biorefinery for bioenergy production: advantages, application constraints, and perspectives. J Environ Manage 296:113194.

10. Pandey A, Soccol CR, Nigam P, Soccol VT, Vandenberghe LP, Mohan R (2000) Biotechnological potential of agro-industrial residues. II: cassava bagasse. Bioresour Technol 74(1):81-87.

11. Capolupo L, Faraco V (2016) Green methods of lignocellulose pretreatment for biorefinery development. Appl Microbiol Biotechnol 100(22):9451-9467 
12. Ahmad S, Pathak VV, Kothari R, Singh RP (2018) Prospects for pretreatment methods of lignocellulosic waste biomass for biogas enhancement: opportunities and challenges. Biofuels 9(5):575-594

13. Ferreira JA, Taherzadeh MJ (2020) Improving the economy of lignocellulose-based biorefineries with organosolv pretreatment. Bioresour Technol 299:122695.

14. Mondylaksita K, Ferreira JA, Millati R et al (2020) Recovery of high purity lignin and digestible cellulose from oil palm empty fruit bunch using low acid-catalyzed organosolv pretreatment. Agronomy 10(5):674

15. van Osch DJ, Kollau LJ, van den Bruinhorst A, Asikainen S, Rocha MA, Kroon MC (2017) Ionic liquids and deep eutectic solvents for lignocellulosic biomass fractionation. Phys Chem Chem Phys 19(4):2636-2665

16. Xu F, Sun J, Wehrs M, Kim KH, Rau SS, Chan AM et al (2018) Biocompatible choline-based deep eutectic solvents enable onepot production of cellulosic ethanol. ACS Sustain Chem Eng 6(7):8914-8919

17. Bulkan G, Ferreira JA, Taherzadeh MJ (2021) Retrofitting analysis of a biorefinery: integration of 1 st and 2nd generation ethanol through organosolv pretreatment of oat husks and fungal cultivation. Bioresour Technol Rep 15:100762.

18. Karimi S, Mahboobi Soofiani N, Mahboubi A, Taherzadeh MJ (2018) Use of organic wastes and industrial by-products to produce filamentous fungi with potential as aqua-feed ingredients. Sustainability 10(9):3296

19. Goh CS, Tan HT, Lee KT, Brosse N (2011) Evaluation and optimization of organosolv pretreatment using combined severity factors and response surface methodology. Biomass Bioenergy 35(9):4025-4033

20. Florian TDM, Villani N, Aguedo M et al (2019) Chemical composition analysis and structural features of banana rachis lignin extracted by two organosolv methods. Ind Crops Prod 132:269-274

21. Mondylaksita K, Ferreira JA, Budhijanto W et al (2021) Enhanced volatile fatty acid production from oil palm empty fruit bunch through acidogenic fermentation-a novel resource recovery strategy for oil palm empty fruit bunch. Fermentation 7(4):263

22. Döner A, Solmaz R, Özcan M, Kardaş G (2011) Experimental and theoretical studies of thiazoles as corrosion inhibitors for mild steel in sulphuric acid solution. Corros Sci 53(9):2902-2913

23. Park N, Kim HY, Koo BW, Yeo H, Choi IG (2010) Organosolv pretreatment with various catalysts for enhancing enzymatic hydrolysis of pitch pine (Pinus rigida). Bioresour Technol 101(18):7046-7053

24. Girgis BS, El-Hendawy ANA (2002) Porosity development in activated carbons obtained from date pits under chemical activation with phosphoric acid. Microporous Mesoporous Mater 52(2):105-117

25. Li K, Zheng Z, Li Y (2010) Characterization and lead adsorption properties of activated carbons prepared from cotton stalk by onestep $\mathrm{H}_{3} \mathrm{PO}_{4}$ activation. J Hazard Mater 181(1-3):440-447

26. Shui T, Feng S, Yuan Z, Kuboki T, Xu CC (2016) Highly efficient organosolv fractionation of cornstalk into cellulose and lignin in organic acids. Bioresour Technol 218:953-961

27. Xu F, Sun JX, Sun R, Fowler P, Baird MS (2006) Comparative study of organosolv lignins from wheat straw. Ind Crops Prod 23(2):180-193

28. Hu P, Zhang Y, Huang J, Liu T, Yuan Y, Xue N (2018) Eco-friendly leaching and separation of vanadium over iron impurity from vanadium-bearing shale using oxalic acid as a leachant. ACS Sustain Chem Eng 6(2):1900-1908

29. Lee JW, Rodrigues RC, Kim HJ, Choi IG, Jeffries TW (2010) The roles of xylan and lignin in oxalic acid pretreated corncob during separate enzymatic hydrolysis and ethanol fermentation. Bioresour Technol 101(12):4379-4385
30. Yan Y, Zhang C, Lin Q, Wang X, Cheng B, Li H, Ren J (2018) Microwave-assisted oxalic acid pretreatment for the enhancing of enzyme hydrolysis in the production of xylose and arabinose from bagasse. Molecules 23(4):862

31. Sluiter A, Hames B, Hyman D, Payne C et al (2008) Determination of total solids in biomass and total dissolved solids in liquid process samples. National Renewable Energy Laboratory 9:1-6

32. Sar T, Ferreira JA, Taherzadeh MJ (2020) Bioprocessing strategies to increase the protein fraction of Rhizopus oryzae biomass using fish industry sidestreams. Waste Manage 113:261-269

33. Lu Y, Mosier NS (2007) Biomimetic catalysis for hemicellulose hydrolysis in corn stover. Biotechnol Progress 23(1):116-123

34. Mosier NS, Ladisch CM, Ladisch MR (2002) Characterization of acid catalytic domains for cellulose hydrolysis and glucose degradation. Biotechnol Bioeng 79(6):610-618

35. Kalogiannis KG, Matsakas L, Aspden J et al (2018) Acid assisted organosolv delignification of beechwood and pulp conversion towards high concentrated cellulosic ethanol via high gravity enzymatic hydrolysis and fermentation. Molecules 23(7):1647

36. Li Z, Fei B, Jiang Z (2014) Comparison of dilute organic and sulfuric acid pretreatment for enzymatic hydrolysis of bamboo. BioResources 9(3):5652-5661

37. Sidiras D, Koukios E (2004) Simulation of acid-catalysed organosolv fractionation of wheat straw. Bioresour Technol 94(1):91-98

38. Huijgen WJ, Smit AT, Reith JH, Uil HD (2011) Catalytic organosolv fractionation of willow wood and wheat straw as pretreatment for enzymatic cellulose hydrolysis. J Chem Technol Biotechnol 86(11):1428-1438

39. Yawalata D, Paszner L (2004) Anionic effect in high concentration alcohol organosolv pulping. Holzforschung 58:1-6

40. Pan X, Xie D, Kang KY, Yoon SL, Saddler JN (2007) Effect of organosolv ethanol pretreatment variables on physical characteristics of hybrid poplar substrates. In Applied Biochemistry and Biotecnology (pp. 367-377). Humana Press. Totowa, New Jersey, USA.

41. Geng A, Xin F, Ip JY (2012) Ethanol production from horticultural waste treated by a modified organosolv method. Bioresour Technol 104:715-721

42. García A, Alriols MG, Llano-Ponte R, Labidi J (2011) Energy and economic assessment of soda and organosolv biorefinery processes. Biomass Bioenergy 35(1):516-525

43. Sun Y, Cheng J (2002) Hydrolysis of lignocellulosic materials for ethanol production: a review. Bioresour Technol 83(1):1-11

44. Chotirotsukon C, Raita M, Champreda V, Laosiripojana N (2019) Fractionation of sugarcane trash by oxalic-acid catalyzed glycerolbased organosolv followed by mild solvent delignification. Ind Crops Prod 141:111753.

45. Marhendraswari MD, Mondylaksita K, Millati R, et al. (2020). Production of edible fungal (Rhizopus delemar CBS 145940) biomass from organosolv-pretreated oil palm empty fruit bunch (OPEFB) in submerged fermentation. In IOP Conference Series: Materials Science and Engineering 991(1):012041.

46. Sues A, Millati R, Edebo L, Taherzadeh MJ (2005) Ethanol production from hexoses, pentoses, and dilute-acid hydrolyzate by Mucor indicus. FEMS Yeast Res 5(6-7):669-676

47. Sar T, Ozturk M, Taherzadeh MJ, Ferreira JA (2020) New insights on protein recovery from olive oil mill wastewater through bioconversion with edible filamentous fungi. Processes 8(10):1210

48. Sar T, Ferreira JA, Taherzadeh MJ (2021) Conversion of fish processing wastewater into fish feed ingredients through submerged cultivation of Aspergillus oryzae. Systems Microbiology and Biomanufacturing 1(1):100-110

49. Karimi S, Mahboobi Soofiani N, Lundh T et al (2019) Evaluation of filamentous fungal biomass cultivated on vinasse as an alternative nutrient source of fish feed: protein, lipid, and mineral composition. Fermentation 5(4):99 
50. Souza Filho PF, Zamani A, Taherzadeh MJ (2019) Edible protein production by filamentous fungi using starch plant wastewater. Waste Biomass Val 10(9):2487-2496

51. Sidiras D, Politi D, Giakoumakis G, Salapa I (2022) Simulation and optimization of organosolv based lignocellulosic biomass refinery: a review. Bioresour Technol 343:126158.

52. Zhou Z, Lei F, Li P, Jiang J (2018) Lignocellulosic biomass to biofuels and biochemicals: a comprehensive review with a focus on ethanol organosolv pretreatment technology. Biotechnol Bioeng 115(11):2683-2702
53. Dessbesell L, Paleologou M, Leitch M, Pulkki R, Xu CC (2020) Global lignin supply overview and kraft lignin potential as an alternative for petroleum-based polymers. Renew Sust Energ Rev 123:109768.

54. Lora JH, Glasser WG (2002) Recent industrial applications of lignin: a sustainable alternative to nonrenewable materials. J Polym Environ 10(1):39-48

Publisher's note Springer Nature remains neutral with regard to jurisdictional claims in published maps and institutional affiliations. 